\title{
Oxidative stress in children with nephrotic syndrome
}

\author{
Om P. Mishra $\cdot$ Franz Schaefer
}

Received: 17 September 2011 / Accepted: 19 September 2011 /Published online: 8 October 2011

(C) IPNA 2011

Sir,

The letter to the editor by Kaneko and colleagues reporting changes in urinary 8-hydroxydeoxyguanosine (8-OH-DG) in idiopathic nephrotic syndrome adds further important information to the role played by oxidative stress in acute glomerular disease [1].

Free radicals are extremely reactive compounds that interact with lipids, proteins, and nucleic acids. The kidney physiologically generates a small amount of reactive oxygen species (ROS) as part of oxidative metabolism, which is well tolerated. If generated in larger amounts locally, ROS may conceivably cause or contribute to the damage of glomerular structures, leading to altered glomerular permselectivity.

Whereas the increased plasma levels of malonyldialdehyde and nitrite observed by us and others in acute nephrotic syndrome signal increased lipid and protein peroxidation $[2,3]$, the increased urinary excretion of $8-\mathrm{OH}-\mathrm{DG}$ as observed by Kaneko et al. reflects the interaction of ROS with cellular DNA [1]. Hence, their finding nicely complements the concept of an imbalance of ROS induction and impaired antioxidant mechanisms in acute nephrotic syndrome $[2,3]$. With respect to the specificity of this potential pathophysiological mechanism, it is of note that no increase in 8-OH-DG occurred in three patients with acute poststreptococcal glomerulonephritis. If this preliminary observation is confirmed, it would lend support to a specific role of oxidative stress in idiopathic nephrotic syndrome.

\section{References}

1. Kaneko K, Kimata T, Takahashi M, Shimo T, Tanaka S, Tsuji S (2011) Change in urinary 8-hydroxydeoxyguanosine in idiopathic nephrotic syndrome. Pediatr Nephrol. doi:10.1007/ s00467-011-2031-6

2. Mishra OP, Gupta AK, Prasad R, Ali Z, Upadhyay RS, Mishra SP, Tiwary NK, Schaefer FS (2011) Antioxidant status of children with idiopathic nephrotic syndrome. Pediatr Nephrol 26(2):251-256

3. Fydryk J, Jacobson E, Kurzawska O, Małecka G, Gonet B, Urasiński T, Brodkiewicz A, Bukowska H (1998) Antioxidant status of children with steroid-sensitive nephrotic syndrome. Pediatr Nephrol 12(9):751-754
O. P. Mishra $(\triangle)$

Department of Pediatrics, Institute of Medical Sciences,

Banaras Hindu University,

Varanasi 221005, India

e-mail: opmpedia@yahoo.co.uk

F. Schaefer

Division of Pediatric Nephrology,

Centre for Pediatric and Adolescent Medicine,

Heidelberg University Medical Centre,

Heidelberg, Germany 